\title{
Employing Open Innovation Where Smes Need It Most, The Indonesian Perspective
}

\author{
Eka Sudarmaji \\ Faculty Economic \& Business, University of Pancasila, Indonesia
}

\begin{abstract}
The Indonesian SMEs is forced to face the hard and brutal competitions through the implementation of ASEAN Economics Community as one single market and free trade agreement, causing reduction of market obstacles in neighboring countries. Innovation is the key to winning over the harsh competition, whereby nowadays 'open innovation' is the key lead in companies' managerial supervision in terms of profitability and sustainable growth. This study introduces implication findings from the application of 'open innovation' on SMEs entrepreneurs as successfully proposed by Henry Chesbrough a decade ago. The evidence will be useful as an input for Government through its policy, companies' associations, and SMEs entrepreneurs themselves, in order to give useful contributions toward their business and aggregated national economy. The empirical investigation is based on a sample selection of Indonesian SMEs those were got the government grants and has collaborated already with other institution such as a university and an association. In the present of two keys external componentsi.e.government grants\&technological development has been adopted by Indonesian SMEs, this study investigateswhether $R \& D$ capacity coupled with significant Managerial Structure and Competencies were the key factors that contribute to developing the innovation capability and export performance of SMEs.
\end{abstract}

Keywords: business performance, open innovation, SMEs

\section{Introduction}

As discussed in many areas, the ASEAN Economics Community ("AEC") emerged in 2016 without any boundaries, which causes all ASEAN companies to compete with each other in a single ASEAN market. As ASEAN go from emerging to surging, Indonesia is destined to play a central role, representing almost 40 percent of the region's economic output as a member of the G20. Indonesia has a pivotal market and has the lion's heart in AEC role, undeniable trends like urbanization and consumerism will absolutely put us in the spotlight. In addition to AEC, In August 2015 Indonesia combine with other 9 ASEAN members have establishedthe "Regional Comprehensive Economic Partnership ("RCEP") together with sixcountries, which are Australia, New Zealand, People Republic of China, India, Japan, and Korea. In another place, the accord of Trans-Pacific Partnership ("TPP") with the US and the other 10 Pacific-Rim nations has been signed and become largest regional trade accord in history. However, the debate around RCEP, TPP and include AEC has mostly concerns on Indonesia's readiness to consider on so many international standards required by the agreements. When compared to neighboring countries such as Singapore, Malaysia, and Thailand, Indonesia is often perceived to be lacking in competitiveness in terms of infrastructure and human resources. In global competitiveness 2015-2016 as stated on World Economic Forum 2016, Indonesia is ranked at 37 (2015-2016 ranking) out of 140 countries, which slightly fell 3 steps from ranked at 34 (2014-2015 ranking) at last year position.

Pros and cons over the benefits of having access to markets of opponent countries and potential costs may come from joining due to the increase in competition and market regulation. Under free trade partnership especially TPP, Small Medium Enterprises ("SMEs") will receive so many support to penetrate the USA market. The TPP will also increase cooperation between different business sectors in many areas such as production and supply chain, connect the business activities as well as contact the end clients. At the end, it will reduce poverty and increase the development in Human Resources. Diversification in the business sectors under the free trade partnership will create hugeopportunities innew markets at domestic and abroad for SMEs. The potential business sectors that are more likely to get gains are information technology sectors, e-commerce, and financial services that are suitable for Indonesian middle class.

The definition of small businessis taken from Government Law No:8/2008, stating that small and medium enterprise ("SMEs") as independent business activities which are done by the individual or business entity that has not become a subsidiary or a branch of other company or being controlled or be a part either directly or indirectly from Medium or Large Business Enterprises. Indonesian SMEs has faced similar problems as other big businesses. These hard and brutal competitions are also forcing many Indonesian SMEs to prepare such "Pre-Mortem" through radical changes in their business operation, and through "Pre-Mortem", SMEs identify what could kill them in the next five years and take appropriate action (Klein, 2007). Most of SMEs in Indonesia forget to implement such thing in a very simple way. The rigorous battling to survive through this 
competition is becoming SMEs' day-to-day activities. Whether they are ready or not, willing or not - they need to prepare to be able to win the war.

Coupling with these new competitions, Indonesian SMEs also need to face abundant obstacles like other modern companies have. The business model needs to rebalance frequently, as the company needs to survive and look at the sustainable growth in the future. Merely due to customer changes and the introduction of the disrupted technology, such as digital technology, has changed the business landscape dramatically and put directly in front of SMEs. Again, our SMEs has been forced to prepare flank attack competition from this new competition, prepare tough and aggressively from the current competitors as well as preparing competition from their own clients. Only the SMEs who are prepared to continuously innovate their products and their services, as well as their processes using technology innovation are able to win the competition.

\subsection{Free Trade Agreement and Innovation}

The effect of Free Trade Agreement ("FTA") towards the innovation of SMEs in Indonesia cannot be avoided. The question that must be answered is whether FTA develops 'innovation' for SMEs or not. Can FTA provide 'benefits' for the SMEs? A Similar question that must also be answered is whether the government regulations in the liberating market and investment will increase the innovation of SMEs and are they able to compete globally. One of the relationships between FTA and innovation is through import and direct investment by the foreign investors - Foreign Direct Investment ("FDI"). The removal of trading barriers in free-market will surely increase competition in the domestic market, decreasing company's market share or even reduce the profit of the companies in the nation. This is a challenge for the domestic companies to increase their efficiency (ASEAN Secretariat, 2011). On the other hand, as stated above, FTA can open up many 'opportunities' for companies or SMEs in increasing relationship between companies within the free-trade region as a global supply chain and become a part of the world's main production.

Thus, the relationship between FTA and innovation should have positive impacts. The most real and most direct effect on increasing export and import is the increase in innovation that is done by companies especially in the form of R\&D, patent, trademark, licensing through tight competition, technology transfer, learning, and spillovers. The effect on the increase of trading and investment in innovation, according to (Onodera, 2008) OECD Trade Policy Working Paper No. 72, 07-Aug-2008.

\subsection{Novelty of Open Innovation}

The innovation has been shifted from closed to open dimension. A decade ago, Henry Chesbrough (2003), the author and the father of Open Innovation said that the key elements of "Open-Innovation" model posts are that important inventions were coming from the inside and the outside of the firm. Open innovation is cleardefined as "the use of inflows and outflows of knowledge to spurs the innovation, as well as to develop the markets". These ideas should then be commercialized both using the current business model and with alternative business models (Chesbrough, 2003).

By using external and internal actors and information for successful value creation, enterprises must look beyond their organization's capabilities because open innovation is claimed to be the new type of innovation. Primarily, there is evident from this longitudinal study; open innovation has so far been adopted mainly in high-tech and multinational enterprises. There is evidence that a few studies have demonstrated that open innovation also exists in the SMEs (Wynarczyk, 2013).

Open innovation is becoming a popular issue in innovation management. Moreover, open innovation is increasingly taking a lead in enterprise management in terms of sustained organization and profitability. There are two main standpoints that they split into two i.e. the scholar who emphasize novelty of open innovation and superiority over the closed one and the scholars who critics and questions the novelty of open innovation by pointing to previous theories and ambiguity of the term of open innovation (Altmann \& $\mathrm{Li}, 2011$ ). There are many supports for the ones who moved from close innovation into open innovation(Enkel \& Gassmann, 2010). On the other hand, there are arguments stating that the open innovation concept can be traced even before they were labeled as"Open Innovation" (Huizingh, 2011; O'Reilley, 2010). The researchers has been divided into two schools, the ones that are in "favor" and the ones that are "against", hence Altman \& Kampe (2010) considered that the rising popularity of open innovation have led to many misinterpretations of any open business event or industry collaborative as Open Innovation, adding an element of confusion about what open innovation is and its perceived novelty (Altmann \& $\mathrm{Li}, 2011$ ).

The "open-innovation firm" and "closed-innovation firm" arearrivingas the result of the consequence of "innovation practices" implemented within the organization. Although the definition of open innovation is widely recognized by most businessmen and researchers, the practices of open innovation were not merging yet. The core in open innovation processes consist of "Inbound process", "outbound process" as well as "coupled process" was defined by Engkel et al. (2009) that may lead the important impacts on company's business performance.On the other hand, the key of internationalization, as the one of the most significant measures of 
business performance and the competitiveness of SMEs is an "Exporting capability". An "inbound process" is based on the capability of the company to adds on its own knowledge-based through internal networks with their suppliers, customers and/or collaboration with other external institutions (e.g. university or associations). Meantime the "outbound process" refers to creating and increasing the profits by transferring innovative ideas to outside by selling or licensing out intellectual property ("IP").

Most researchers discuss the adoption of open innovation strategies in the form of practices and applying on innovation technologies. They focus on 'inter-firm cooperation', 'cooperation with intermediary institution', 'cooperation with research organization', 'management attitude', 'planning and external orientation', 'R\&D alliances' and finding the effect of open innovation strategies on SMEs. Meanwhile, O'Regan et al. (2006) has found out that 'strategy', 'organizational culture', 'leadership', and 'innovation' has a big role in becoming in innovation (O'Regan, Ghobadian, \& Sims, 2006). Laforet (2078) argued that 'size', 'strategy' and 'market orientation' plays a bigger role in achieving innovation (Laforet, 2007).Especially in the SMEs, the entrepreneur level has increased in the implementation of open innovation strategies. The component of management aspect, indicators, and technological innovation are widely measured. The four factors that are related to foreseeing the entire management and to measure open innovation successfully are objective market acceptance, subjective market acceptance, financial performance, and product-level-measures (Huang, Soutar, \& Brown, 2004).

\subsection{Open Innovation in Indonesia SMEs}

Gassmann, Enkel and Chesbrough (2010), found that one of the future trends of Open Innovation, which has been identified stated that Open Innovation had shift from large firms to SMEs. They thought that some SMEs are able to handle their 'liability of smallness' by catching up their innovation process(Keupp \& Gassmann, 2009; van de Vrande, de Jong, Vanhaverbeke, \& de Rochemont, 2009).Theaffordabletechnology can make the core competence for those SMEs. Implementation of open innovation that has been successful in enterprises often comes with arguments about the critical challenges for the development of SMEs (Lazzarotti, 2008). SMEs can be classified openly to the implementation of open innovation due to their size and nature. The challenging competition and more demanding customers have become a motivation for SMEs.

The study conducted by PPM School of Management's Center for Innovation and Collaboration (Jakarta Post, 11th Dec, 2014), revealed that Indonesia's competitiveness is believed to have competitive edge on a bigger stage in the lead-up to implementation of the ASEAN Economic Community ("AEC"), as the country has the chance to develop innovations in its area of expertise. Indonesia needs to reorient its focus on human resources based, which would emphasize individuals as innovation agents. The new administration needs a huge amount of innovative and creative research to implement it to the SMEs sectors.

Innovations within SMEs in Indonesia are not those that happen within big companies, the innovation is not practiced and implemented in their daily activities nor is it stated in their business plan. It is the innovation that has not been implemented into their routines or cultured within their organization. The innovation has only happened through several stakeholders. The innovations rooted through individuals who think that innovation will be useful for their companies. Indonesian' SMEs are typically born, grow and expand to export operation from small company establish in such cluster are usually in Jogyakarta, Cirebon, Trangsang-Solo, Tanggerang \& many other places in Indonesia. Innovation in Indonesian SMEs is not truly daily practices \& mindset, handto-hand and melting down in their organization and only takes place through a few of stakeholders.

The innovation sparks through the individual who thought that it would useful for the company. These individuals mostly come and gain experiences from the big company. Therefore,Maverick style is very dominant in the Indonesian' SMEs afterword. Trial \& error activities in their product innovation probably became the management view's combine with tight measure of performance for every manager to operate the business unit. The advantages of the maverick style can be defined as 1) Maverick Style Innovation create low cost and measurable investment, 2) Innovation can take short time and easily to measure financially, and 3) People in Indonesian' SMEs are coming from different education, behavior \& culture. It is difficult to involveeveryone into the process. On the other hand, the disadvantages can be drawn as1) Innovation is "Discipline", not just process. By implement continuously innovation, the company can get benefit from hard competition. Doing "Maverick-style" can be one-off innovation happened in the organization. "Trial \&Error" will dominate the process as well as the final products as result of those innovations, 2) Innovation takes place only when maverick person is available and such complicated implementation can happen if most of the people involve rejected his/her idea, and 3) Continuously innovation will probably erode the financial ability. 


\section{Methods}

The research strategy used in this paper is case studies, subsequently detailed information that provides sampling using primary data. The result will use multi layers data in order to identify the phenomenon of change. The rationale decision to choose case studies is based on the ability to replicate analysis in order to obtain either the confirmation of the theoretical existence or contrasted findings of selected cases. The primary data is the questionnaire ("questionnaire"), and in this case, the research instruments were distributed directly to the business actors randomly. The questionnaires are the standard; the respondents are asked exactly the same questions in the same order and the results tend to consistent. It's easy and reliable. Meanwhile, the comparative analysis is employed as the main function to analyze the data line by line to capture the concepts and the relationships all variables.

This paper will assessthe practices, especially on "Export Capability" of Indonesian SMEs as aproxy of international competitiveness of SMEs. This paper will not analyze the present of a few of external key components, government grants\& technological development had adopted by Indonesian SMEs already. But instead, this paper analyzeswhether the "Exporting Capability" of SMEs in Indonesia is affected by the cumulative effects and interrelationship two key internal components, i.e. R\&D capacity and managerial structure and competences that ability to contribute to the development of innovation capability and export performance of SMEs. Hence, this paper adopted the general assumptions that two key external factors, i.e. open innovation practices and the ability of the firm,attract government grants and technological development has been embedded by Indonesian SMEs even thoughon a small portion.

As Henry Chesbrough (2003), stated that "Open-Innovation Companies" is able to use purposive inflows \& outflows of knowledge to accelerate internal innovation, and to expand the markets.Putting these samples of the study that were taken from the company that has received lots of good deeds from the government, nation's company (BUMN) association and even a few of them have done a collaboration with several universities to held a management or marketing training. The form of aids that has been given is not only training but also the free exhibition, cash loan, and also loan to buy machinery or even a gift in a form of production equipment. Thus, according to the Chesbourgh definition (2003), these company samples that has been used in this study can be categorized as the company that has done an open innovation practice and can be considered as open innovation SMEs. This study is conducted merely to investigate whether after these companies can gain help, this will develop the companies' capabilities to increase their export capabilities.

Hopefully, this paper will have the impact that can measure and predict open innovation capability and export performance of SMEs.The use of Export Capability for SMEs will be the keyword difference for this paper. This paperaims to assess the effects and challenges that arise from two key components on Export Capability as a proxy of international competitiveness of SMEsas well as on their SMEs business performance. There are interrelationships between two key components: 'Internal Context' that we need to estimate \& investigate.

H1. In the present of Government Grants\& Information Technology (Development)implementation as well as open innovation practices, this study is going to analyze whether the SMEs competitiveness of innovative is "Exporting" as a proxy business growth performanceare affected by two components that are R\&D capacity and Management Structure \& Competences. The hypothesis of business performance is therefore evaluated by using empirical data that involves customers, employees \& customers as the media to assess SMEs business performances as the independent variable.

H2. To evaluate whether after controlling H1, there is any significant difference between the SMEs those are able to "Export Capability", as a means of survival, growth and gaining the position over domestic-oriented SMEs. Export capability or Internationalization is going to discriminate both of them. Additionally, the organization performance of each SMEs will be grouping.

Primarydata of this paper are achieved through closed and open-ended questionnaire. The research populations are SMEs that are listed within 'associations'. Research samples are determined based on purposive sampling by criteria (a) registered with training program and promotion subsidy from government, whether it is from association, local government, or central government or government-related companies, (b) included in the criteria and characteristics of SMEs according to Government Regulation no.9/2008, (c) the company has operated and run for a minimum of two years before the survey is taken. The denomination of 'open SMEs' is simply based on our surveyed firms actively participated in received support ('inbound process') from other firms or association or governmentthat resulted in innovations, commercialization and/or new product development at the time of survey conducted.

The locations of two research samples were taken in three places: Kunming, Nanning \& Bandung. Two samples were taken in Kunming, Yunnan-PRC, and Nanning, Guangxi-PRC who attend the exhibition that was subsidized by the Ministry of Commerce. Theses SMEs are grouping into the companies that already implemented exporter activities or internationalization as one of open innovation practices. While the other 
samples were taken under the coordination and guidance of PT. "T" who are running business competition training and workshop on 27-29 October, 2016 in Bandung, Indonesia. For the purpose of this publication the PT. "T" names have been changed to maintain confidentiality and to provide a descriptive title. Theses SMEs are grouping into the companies that already implemented marketing or management strategies activities (new product or new service development) as one of open innovation practices application. Below are a few obstacles faced by these SMEs upon receiving the grants and collaborations with other institution therefore they cannotable to spur the innovation within their operation.

Table 1. Statistical Descriptive of Main Obstacle of Open Innovation

\begin{tabular}{|r|l|c|c|}
\hline No & Obstacle for Doing innovation Practices & Mean & STD \\
\hline 1 & Limited Budget or Fund & 1.5263 & 1.3098 \\
\hline 2 & Limted Loan & 1.3684 & 1.2175 \\
\hline 3 & Resulting in High Cost & 1.2105 & 1.2554 \\
\hline 4 & Hisgh Risk on Innovation & 1.0526 & 1.1377 \\
\hline 5 & Hard to Find Partner & 0.9737 & 1.0777 \\
\hline 6 & Uncertainty Demand of Products & 0.9737 & 1.0777 \\
\hline 7 & No Skilled Resources & 0.8684 & 1.0180 \\
\hline 8 & Competitors Dominate the Market & 0.8684 & 0.9911 \\
\hline 9 & No IT Technology & 0.8421 & 0.9733 \\
\hline 10 & No Marketing Staff & 0.7368 & 0.8601 \\
\hline
\end{tabular}

Value: $0=$ Null, $1=$ Low, $2=$ Medium \& 3=High

The first samples were taken from the Indonesian SMEs exhibitors that attended the 24th China Kunming Import and Export Fair (Kunming Fair) 2016, which was held on June 12-16, 2016 in Kunming Dianchi International Convention \& Exhibition Center (KDICEC), People's Republic of China. The total of 17 questionnaires was distributed but only 12 exhibitors returned back the paper (responds rate $70.59 \%$ ). The second questionnaires were distributed among the Indonesian SMEs delegation at the 13rd China Asean Expo (CAEXPO) 2016 in Nanning, Guangxi at 11-14 September 2016,in CAEXPO International Convention \& Exhibition Center, People's Republic of China. The total of 29 questionnaires were distributedto furniture \& accessories companies but only 12 exhibitors returned it back (responds rate $41.38 \%$ ). The last questionnaires were distributed among the SMEs under the guidance of PT. " $\mathrm{T}$ " that was done in Bandung, Indonesia. The total of 35 questionnaireswas distributed and only14companies returned back (responds rate 40\%). This study was built on the theories of conceptual while developing a structural model to look at the variables that affect the export capability strategies, which bolster the sustainability of business performance. The first step is determining the variables involved in open innovation strategies based on our framework, and then test the model of the relationship between variables in conjunction between the open innovation strategies and export capability. The variables involved in this study consisted of two independent variables and one dependent variable. Both independent variables are the R\&D Capacity (RD) and Management Structure \& Competences (MSC) that are available in the current environmentand Internationalization/ExportingCapability (IE) as a proxy forSustainable Growth Performance. Hypothetical models describe the relationship between these variables as shown in figure 1.

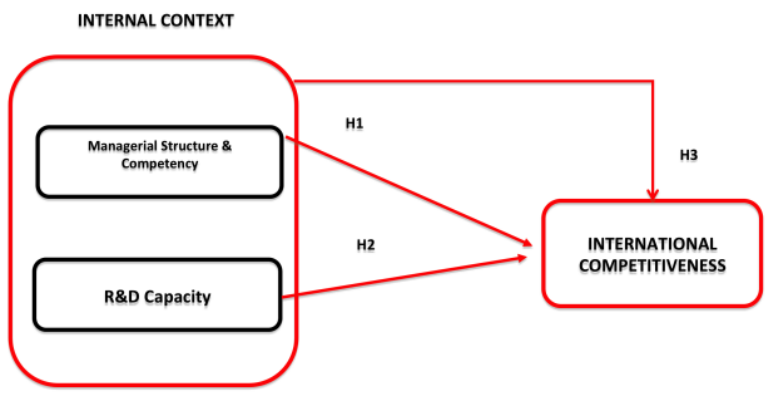

Figure1. Research Model

The data in this study consisted of qualitative data. This paper will be limiting the research within the context of International Competitiveness for open innovation strategies for Indonesian SMEs to provide better products (product innovation) and services (service innovation) through better processes (process innovation) as well as technologies (technology information). Another limitation is the context of the keys internal componentsthat are available during the period of study. Overall, this paper develops under the assumption that all the open innovation practices in Indonesian SMEs need to identify and implement it.

DOI: $10.9790 / 487 X-1905020616 \quad$ www.iosrjournals.org $\quad 10 \mid$ Page




\section{Result And Discussion}

The research results show that all open innovation practices in Indonesian SMEs were involved in "inbound" open innovation processes only. Some SMEs were involved in knowledge and information exchange, collaborative R\&D, new product development, and marketing of new product(s). Un-opportunity "outbound" and "coupled" open innovation processes were not popular among the Indonesian SMEs - for example, Selling and franchising out intellectual property (IP), joint patenting, cross-shareholding and joint venture. The joint activities with suppliers and customers were mainly in the areas of marketing and new product development.

Open Innovation Practices do not depend on R\&D Capacity and Management Structure \&Competences only but on the cumulative of several related Intra organization components. Below is the form of Open Innovation Practices collaboration between company and suppliers, customers \& local institution such as business associations and university. It can be seen in the figure 2, open innovation practices that were done by the SMEs in their businesses to hold a new product launching, new products, and increase efficiency in new fabrication process were dominant.

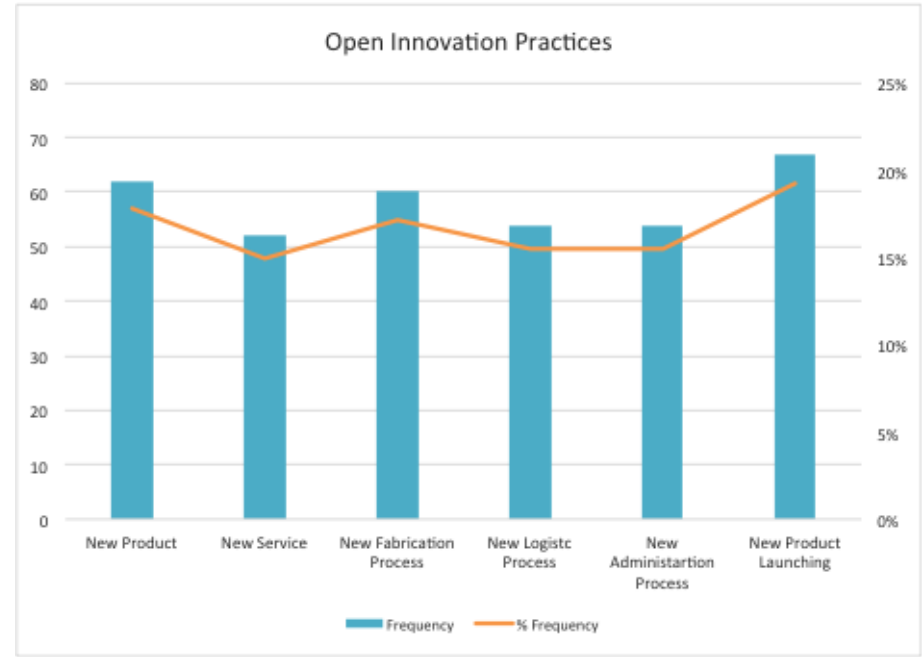

Figure 2. Open Innovation Practices

On the other hand, the most component R\&D Capacity in Indonesian SMEs is the availability of an Internal R\&D, External R\&D or Outsourcing and Purchase New machine, Software or Other Equipment as shown in figure 3. The availability of an Internal R\&D is absolute needed for companies under their operation to develop new products and services. Cohen \& Levinthal (1990), in the concept of "absorptive capacity" saw that investigation in internal R\&D is the main key to access and utilize the knowledge of external and technology. The concept of "absorptive capacity" is the concept that competing with the open innovation concept. While external R\&D or outsourcing are the concepts, where the company good innovations are new products and services or the new process, through the third party while doing job outsourcing. The sales of new machinery, software, and equipment can also improve the company's innovation skills.

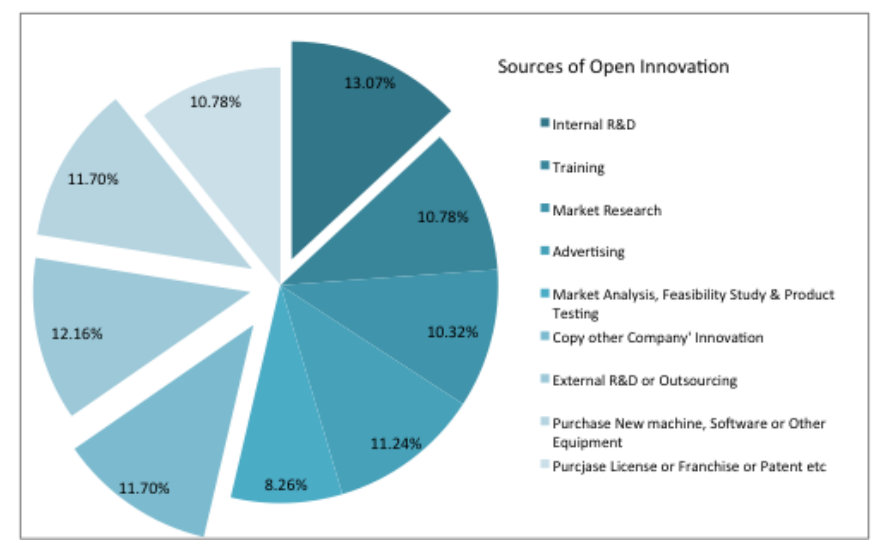

Figure 3. Sources of Open Innovation 
The summaries of the three core open innovation processes: The outside-in process, that is an enriching the company's own knowledge base through the integration of suppliers, customers, and external knowledge sourcing can increase a company's innovativeness. "R\&D capacity and Management Structure \& Competences"were believed to enable SMEs to enhance their innovation capability.

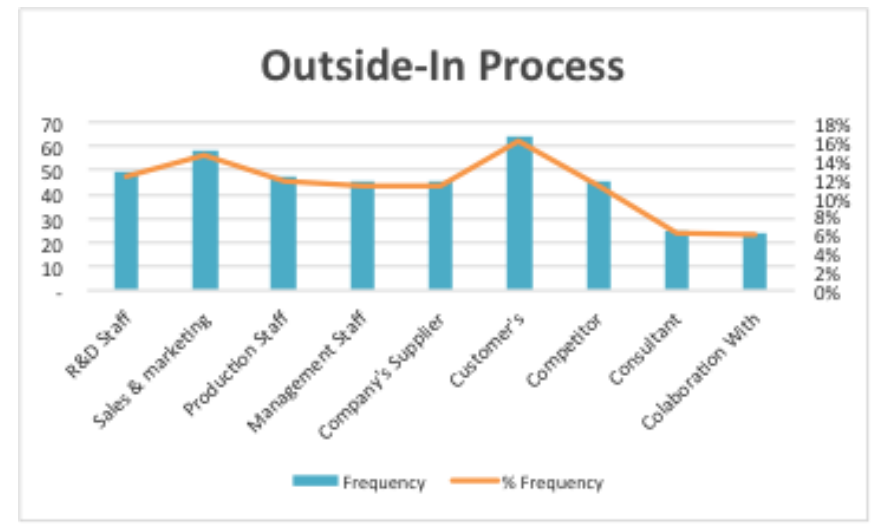

Figure 4. Outside-in Process: Core Open Innovation

The outside-in process can be made into the main competence for SMEs' companies' skills in open innovation. Meaning that SMEs chose to invest on cooperating with the supplier, customers, and outsiders, such as government and universities integrating the external knowledge that was achieved. Open Innovation Practices coupled with Government Grants \&Technological change does not depend entirely on a firm's R\&D capacity but on the cumulative effects of others several related intra-organizational factors. The open innovation indeed needs the management and organization in the innovation processes which in circumstances become more intense. Meanwhile, Managerial Structure and Competency of the organization is changing over time especially in introducing and implementing the modern management techniques and searching for getting the benefits from opening the opportunities from open innovation practices.

Base on the figure 4, Indonesian SMEs tend to cooperate with customers, where the cooperation can be used to develop design-making, design quality and product quality that the customers wanted. This cooperation also increases their skills in innovating, such as developing new products together. In another word, customers are integrated as the source of valuable information and use their competence in developing a new product. Integrating the source of external information and the companies' competence in their effort to start innovation process can become the company's main competence.

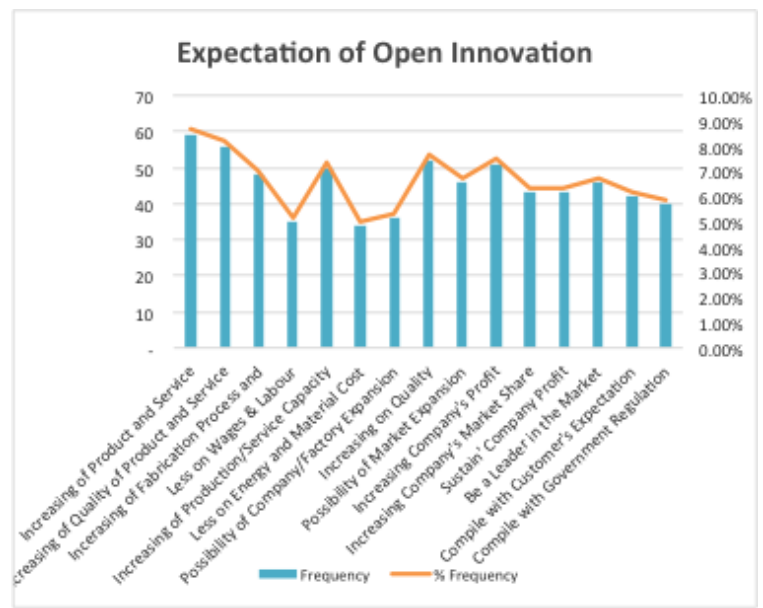

Figure 5. Expectation of Open Innovation Result

Meanwhile,as the stated from Figure 5, the real result of open innovation practices that is desired by Indonesian SMEs is increasing product \& services, increasing production \& service quality, increasing company profit and increasing quality after achieving government's aid and collaborating with other institution.

The inside-out process, earning profits by bringing ideas to market, selling IP and multiplying technology by transferring ideas to the outside environment.Companies that chose "the inside-out process" as a process in the company that focuses on the effort to bring out ideas and innovation to the market in order to 
achieve quicker advantage compared to those they can do through internal development. Companies decided to bring out the company's limitation to produce advantages in licensing IP and/or switching technologies, such as transferring ideas to the companies.

The coupled process: coupling the outside-in and inside-out processes by working in alliances with complementary partners in which give and take is crucial for success. All the three core processes represent an open innovation strategy, but not all are equally important for every SMEs.This paper assesses the business performance and competitiveness of innovative SMEs using a proxy of "exporting", as a key measure of internationalization.

\section{Research Finding}

The empirical results presented below are based on both univariate \&multivariate analyses. The correlation and regression were conductedusing the excel spreadsheet to test hypotheses as well as assessing the significant differences and level of relationships between the variables used in two sub-samples, "exporting capability' and 'no exporting capability' firms. Regression analysis has been undertaken to confirm two hypotheses (H1 \& H2) above, in order to assess the interrelationship between two key internal components and their cumulative effects onexport capability. on univariate technique, namely ' $t$ '-test has been checking for testing the statistical significance of different between the mean values of the two group and thus to test the individual discriminating power of the ratios between the groups. The empirical studies found that two mean values of two variables are significant at 0.05 level of significant. The ' $t$ ' value of two variables is greater than the tabulated ' $\mathrm{t}$ ' value, i.e 3.3080>t $\mathrm{t}_{0.05}$ and 2.8816> $\mathrm{t}_{0.05}$ for "R\&D capacity" and "Number of Staffs/Manager of Sales and Marketing" as a proxy of "Managerial Structure and Competency".

After analyzing and recognizing discrimination and predictive power on the univariate basis, an attempt has been made to test the under mentioned hypothesis on the basis of multivariate analysis. An attempt to derive a linear combination of the variables characteristics which best discriminate between the groups. Once the value the discriminant coefficients are determined, it is possible to calculate discriminant to one of the groups based on the score. The essence of the procedure is to compare the score of an individual firm with that of the alternative group. In this manner, the firm is assigned to the group it most closely resembles.

\subsection{Export Capability Discriminant}

The overall regression shows the direction of the influence of each object of research. The regression coefficient that has a positivesign means "R\&D Capability", and "Managerial Structure and Competency" have positiveeffects on export capability. The equality has 'R-value' or correlation coefficient of 0.3980; Adjusted R square of $0.3636 ; \mathrm{F}$ value of 11.5710 with 0.0001 significance level. The significance value less than 0.01 or $1 \%$ show that these results have the ability to show that "R\&D Capability", and "Managerial Structure and Competency" have the effect on "Exporting Capability".

On the individual variable view, the "Managerial Structure \& Competency" has a significance level of 0.0022 witha " $\mathrm{t}$ " value of 3.3080 , it is less than 0.01 or $1 \%$. This means that "ManagerialStructure \& Competency" has a significant effect on export capabilities for Indonesian SMEs. "Managerial Structure \& Competency" plays an important role in influencing the operation. The number of manager and staffs of sales \& marketing are taking the pivot role for the SMEs as an agent of change or important broker between the company and the markets. Most of them were given the best advice for the company to meet the customers' perceived value of the company's products or the services. Most of the knowledge had been fully absorbed by the company. Secondly, the level of significance of R\&D Capacity amounted to 2.8816 with a " $t$ " value of 0.0067 , it is greater than 0.01 . This means that the R\&D Capacity had a significant effect on export capabilities. Based on the empirical findings, this paper found that these results are consistent with research conducted by Pooran Wynarczyk (2013).

The Z-score (0.6204) reveals that a significantly predictive value of $76.32 \%$ for the SMEs who has "exporting capability" and on the other hand has the predictive value that are even significantly higher with a percentage of $92.86 \%$ for those who owns no "exporting capability". It shows that the two keys of internal components "R\&D Capacity, and Managerial Structure and Competency" has a very strong relationship with the 'exporting capability' as a proxy of international competition or business performances.

Based on the results of the study, it can be summarized as follows: 1) "Managerial Structure \& Competency" has a significant effect on "Export Capability" as a proxy of International Competitiveness. Testing results of significance level are smaller than the standard significance, 2) The "R\&D Capacity" has the significant effect on "Export Capability" as a proxy of International Competitiveness. Results of testing the significance level are greater than the standard significance, 3) "Managerial Structure \& Competency" and the "R\&D Capacity" have a significant effect on "Export Capability" as a proxy of International Competitiveness. Results of testing the significance level are smaller than the standard significance. 
This study only tested two key internal components i.e. the "Managerial Structure \& Competency" and the "R\&D Capacity" as the independent variables, and "Export capability"as the dependent variable, so the author considers that the addition of new variables for future research is needed. Subsequent research may consider other independent variables that are not included in this study.

\section{Discussion}

The world is fundamentally changing, companies including the Indonesian SMEs could make a choice depending on how they view the world and more importantly is the expectation of how Indonesia SMEs should behave and react to customers' needs. Technology has transformed how customer acts, share information and understand the world, and has given consumers power like it has never done before. In this circumstance, all SMEs that have unprecedented experience have to change to a new environment in which they must now work harder on it. Only through open-innovation, Indonesian SMEs are able to survive and win the competition. The liberating market and investment have a positive impact especially in increasing the innovation of Indonesian SMEs in another part of the world.

Ari Kuncoro (2014) stated that there is a positive correlation between new investments in machinery and R\&D activities, purchase of new machinery can be categorized as innovation process, thus producing new $R \& D$ activities in order to adapt to such new machines and the new R\&D activities will bring better production process (Kuncoro, 2016). Government's regulation implication upon import activities of machinery and R\&D activities pushes companies in Indonesia to start innovation process and push these companies to start R\&D that in the end leads them to be able to compete globally.

There is a relation between trading and innovation. One of the obvious, that technological innovation creates competitive advantages within trading. The discrepancy between emerging andadvanced countries' technology, is in trade and. Advanced countries tend to export high-tech products compared to emerging countries. Companies that have innovation will do export, foreign investment, or technological licensing that they own to exploit the benefit of innovation that has been found. Therefore, within the free trade, this will be advantageous to companies that innovate compare to those that do not.

AEC will create bigger market than before, and thus creating companies that innovate to benefit from their own innovation. Free trade and foreign investment affect companies in innovation in many aspects such as employee involvement, external participation, R\&D outsourcing, patent licensing, and intellectual property copyrights.

On the other hand, the relationship between FTA as well as single market AEC and innovation are supposed to be '+' positive. The only '-" negative effect is coming from the scale of the economy since imports can lead to the decrease of the scale of economies. Then scale of economies can be improved if inefficient manufacturers are weeded out in the long run as well as in the medium term if manufacturers are able to increase the exports. Meanwhile, the competition generally enlarged the motivations for manufacturers to innovate. Unfortunately, for manufacturers, which are far below the technology curve, the sudden increase in the competition can decrease innovation. Indeed, the real and direct effect of the increase of export and import is the increase of innovation done within company especially R\&D sector, the increase of 'patent', 'trademark', 'license' through tight competition, technology transfer, studies, and spill-overs. Osamu Onodera (2008), on an article in OECD no. 72, sees many effects of trading and investment in innovation.

Given the aspects of "the internal and the external keys components" are arising from the resultof howliberating the trade between the countries are, the paper also need to check the relationship and 'how important' those connections. At the end, we hope that the result can measure and predict those correlations that will lead us to know further about "Open Innovation Practices" and "Exporting Capabilities of SMEs" and/or "Market Domestically" on Indonesia SMEs.

\section{Conclusion}

This paper assesses only "the internal keys components" of open innovation practices for Indonesian SMEs due to the fast changing environment. The 'Innovation Opportunity Framework' must be developed by IndonesianSMEs using aspects of 'the internal keys components\&the external keys components' on regular based, given that the current and future business environment landscape. By keeping these 'the internal keys components\&the external keys components' of SMEs on open innovation in mind, the innovation opportunity framework needs to be performed under AEC implementation.

In order to survive, the Indonesia SMEs must improve their own innovation activities, either in the form of new product, new service, new process or new technology to satisfy its own customers. But on the other hand, increasing innovation activities upon integration requires more resources to provide, that in the scale of economic will probably not suit (the domestic market's demand). There will probably be companies that are doing a very small amount of innovation. The best example of this situation can be seen as the producers of furniture and household appliance in Indonesia are in a better trade-off to stop their manufacturing and 
profitability just to be a merchant or become an extension of the same industry of the SMEs from China. On the other hand, the opening of export markets causes many Indonesian SMEs to easily export their merchandise, licensing their copyright and investing out in the form of an outward FDI to other countries.

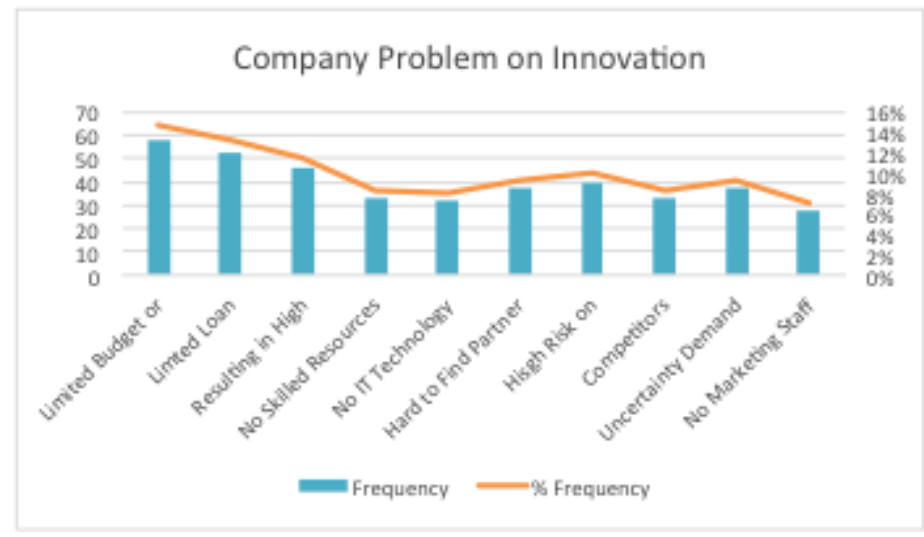

Figure 6. List of Problems on Innovation

The second responsible party that boosts the Indonesian innovation is the governments (regional and national) beside entrepreneurs. Indonesian governments have implemented many regulations to promote innovation including within R\&D, intellectual property, education, market labor, the stock market, as well as product market. The Indonesian government has also realized that encouraging business environment to innovate is the most important aspect. Public regulation, and open trading regulation as well as investment regime, is an important aspect of existing innovation, that is possible for incoming technology, increasing compositions and opening new markets for entrepreneurs. International trading and foreign direct investment are very important to the business environment in Indonesia as a way to exploit innovation.

In the future, the government is expected to enact and take a lot more aggressive role in maximizing the presence of the entrepreneurs of SMEs because the economics of Indonesia are becoming more open. The economic cooperation and trade liberalization should be able to improve the ability of the Indonesian SMEs for innovation so that it can compete fairly. The government's policies on the entrepreneurs of SMEs, which are currently taking more than $90 \%$ of the Indonesian workforce, should be considered as a national policy. Furthermore, the policy on FTA should also provide long-term benefits aspects especially with respect to the transfer of technology that must occur, in which there is the ability of The Indonesian SMEs to grow and create innovation in the form of the ability to set up R\&D by themselves, or in collaboration with other outside parties.

In the World Economic Forum 2016 ranking on countries performance on innovation and sophistication factors, Indonesia is ranked number 37, three steps down last year's rank: number 34. Indonesia as the biggest country in Southeast Asia has its innovation that has become the proof of increasing competitive ability. Government spending from Gross Domestic Product is categorized as a very low, and without further innovation, Indonesia cannot grow any further. Indonesia' public spending for research and development as part of Gross Domestic Product for the year 2005-2014, in comparison to other ASEAN countries, is the lowest around $8 \%$, comparing with the Philippines 11\%, Vietnam 19\%, Thailand 39\%, Malaysia $113 \%$ and Singapore $200 \%$ (world bank).

In the last five years, many factors that cause the emergence of new technology entrepreneurs, is caused by the boost of Internet improvement. Some factors can be identified to push Indonesian SMEs forward especially with the availability of single market of AEC: 1) AEC will improve FDI, which may lead to the increasing demand of supporting goods from small units such as Indonesia SMEs, the business opportunities will increase due to FDI, 2) FDI from overseas linked directly to competition of business and affected the IndonesianSMEs growths, 3) AEC will ease of tariffs and customs, reduced obstacles for trade and the improved technology, pushes Indonesian SMEs to take opportunities overseas.

\section{Future Research}

The future study will still continue to explore a better framework for the practice of Indonesian SMEs that is associated with a new round of free-trade developments, 1) future studies may incorporate findings of different strategies in improving business performances for SMEs in Indonesia; 2) future study could be focused on identifying different opportunities and challenges within dynamics environment; 3) future researcher could pay more attention to the inflows \& outflows of innovation within Indonesian SMEs and other parties. 


\section{Reference}

[1]. Altmann, P., \& Li, J. (2011). The novelty of Open Innovation. School of Business and Engineering (SET), Student Th(Jing Li), 124. http://doi.org/urn:nbn:se:hh:diva-16855

[2]. ASEAN Secretariat. (2011). ASEAN Economic Community Factbook. Jakarta, February. Retrieved from http://www.aseansec.org/wp-

content/uploads/2013/07/ASEAN_AECFactBook.pdflnhttp://scholar.google.com/scholar?hl=en\&btnG=Search\&q=intitle:ASEAN+ Economic+Community+Factbook\#3

[3]. Chesbrough, H. (2003). Open Innovation The New Imperative for Creating and Profiting from Technology. Journal of Chemical Information and Modeling (Vol. 53). http://doi.org/10.1017/CBO9781107415324.004

[4]. Enkel, E., \& Gassmann, O. (2010). Creative imitation: Exploring the Case of Cross-industry Innovation. R and D Management, 40(3), 256-270. http://doi.org/10.1111/j.1467-9310.2010.00591.x

[5]. Huang, X., Soutar, G. N., \& Brown, A. (2004). Measuring new product success: An empirical investigation of Australian SMEs. Industrial Marketing Management, 33(2), 117-123. http://doi.org/10.1016/S0019-8501(03)00034-8

[6]. Huizingh, E. K. R. E. (2011). Open innovation: State of the art and future perspectives. Technovation, 31(1), 2-9. http://doi.org/10.1016/j.technovation.2010.10.002

[7]. Keupp, M. M., \& Gassmann, O. (2009). The past and the future of international entrepreneurship: A review and suggestions for developing the field. Journal of Management, 35(3), 600-633. http://doi.org/10.1177/0149206308330558

[8]. Klein, G. (2007). Performing a Project Premortem. Harvard Business Review, (September).

[9]. Kuncoro, A. (2016). Globalization and Innovation in Indonesian Manufacturing, (May).

[10]. Laforet, S. (2007). Size, strategic, and market orientation affects on innovation. Journal of Business Research, 61(7), 753-764. http://doi.org/10.1016/j.jbusres.2007.08.002

[11]. Lazzarotti, V. (2008). Managing innovation networks of SMEs: a case study. ... Conference, 2008. IEMC ..., (Mi), 1-5. http://doi.org/10.1109/IEMCE.2008.4618024

[12]. O’Regan, N., Ghobadian, A., \& Sims, M. (2006). Fast Tracking Innovation in Manufacturing SMEs. Technovation, 26(2), $251-261$. http://doi.org/10.1016/j.technovation.2005.01.003

[13]. O’Reilley, D. P. (2010). Open Innovation : Past Is Prologue.

[14]. Onodera, O. (2008). Trade and Innovation Project, (72).

[15]. van de Vrande, V., de Jong, J. P. J., Vanhaverbeke, W., \& de Rochemont, M. (2009). Open innovation in SMEs: Trends, motives and management challenges. Technovation, 29(6-7), 423-437. http://doi.org/10.1016/j.technovation.2008.10.001

[16]. Wynarczyk, P. (2013). Open innovation in SMEs. Journal of Small Business and Enterprise Development, 20(2), $258-278$. http://doi.org/10.1108/14626001311326725 